\title{
Expression of Osteopontin and CD44 Molecule in Papillary Renal Cell Tumors
}

\author{
Koviljka MATUSAN, ${ }^{1}$ Gordana DORDEVIC, ${ }^{1}$ Vladimir MOZETIC, ${ }^{2}$ Ksenija LUCIN ${ }^{1}$ \\ ${ }^{1}$ Department of Pathology, Rijeka University School of Medicine, ${ }^{2}$ Department of Urology, \\ Clinical Hospital Center Rijeka, Rijeka, Croatia
}

The aim of the study was to analyze the expression of CD44 adhesion molecule and its ligand osteopontin in papillary renal cell tumors, and to assess the possible prognostic significance of CD44 and osteopontin expression in papillary renal cell carcinomas. The expression of the standard and $v 6$ exon containing isoforms of CD44 molecule, as well as of its ligand osteopontin, was immunohistochemically evaluated in 43 papillary renal cell tumors, which included 5 adenomas and 38 carcinomas. In order to assess their prognostic significance, the results obtained in papillary renal cell carcinomas were compared to usual clinicopathological parameters such as tumor size, histological grade, pathological stage, and Ki-67 proliferation index. Normal renal tissue was negative for CD44s and v6 isoforms, while the expression of osteopontin was found in distal tubular epithelial cells in the form of cyto- plasmic granular positivity. CD44s and v6 isoforms were upregulated in $22(58 \%)$ and $12(32 \%)$ out of 38 carcinomas, respectively. Among all clinicopathological parameters examined, we only found significant association of CD44s-positive carcinomas with lower pathological stage $(p=0.026)$. Papillary renal cell adenomas were generally negative for CD44s, except for focal positivity found in one sample. The osteopontin protein was detected in all adenomas and all papillary renal cell carcinomas, except one. Our results show constitutive expression of osteopontin in papillary renal tumors, including papillary renal cell adenomas. The upregulation of CD44s and v6 isoforms, although found in a considerable number of papillary renal cell carcinomas, does not appear to have any prognostic value in this type of renal cancer. (Pathology Oncology Research Vol 11, No 2, 108-113)

Key words: papillary renal cell carcinoma, cell adhesion, CD44s antigen, CD44v6 antigen, osteopontin, immunohistochemistry

\section{Introduction}

The present classification of renal tumors is based on cytological appearance and the cell type of origin in combination with growth pattern and genetic alterations. ${ }^{8}$ According to this classification, papillary renal cell carcinoma is recognized as a distinct subtype of renal carcinoma, which comprises $10-15 \%$ of cases in surgical series. It is characterized by predominant papillary or tubulopapillary histol-

Received: Aprl 12, 2005; accepted: May 5, 2005

Correspondence: Ksenija LUCIN, Department of Pathology, Rijeka University School of Medicine, Brace Branchetta 20, 51000 Rijeka, Croatia, Tel.: +38551325805, Fax: +38551325810,

E-mail: ksenijal@medri.hr

This work was supported by the Ministry of Science, Education and Sport of the Republic of Croatia (grant 0062066). ogy with fibrovascular cores, including solid variant with sheets of cells that otherwise resemble papillary renal cell carcinoma. ${ }^{2,8}$ Genetic features are characterized primarily by trisomies or tetrasomies 7 and 17 , and $\mathrm{Y}$ chromosome loss in males, as well as additional gains of chromosome $3 \mathrm{q}$, 12, 16, and 20. ${ }^{11,16}$ Delahunt and Eble have proposed subclassification of papillary renal cell carcinoma into type 1 and type 2, according to the cytoplasmic volume and thickness of the lining cells. ${ }^{7,8}$ There is debate concerning the relative outcome of papillary renal cell carcinoma compared to clear cell type, which could probably be resolved by adopting this recently proposed subclassification.

Cell adhesion molecules are involved in various physiological and pathological processes including cancer. Among them, CD44 molecule has received much interest as a major cell adhesion and signaling molecule involved 
Table 1. Relationship between CD44s expression and tumor size, stage, grade and proliferation index

\begin{tabular}{|c|c|c|c|c|c|c|}
\hline \multirow[t]{2}{*}{$\begin{array}{l}\text { CD } 44 \text { s expression } \\
(N o . ; \%)\end{array}$} & \multirow[t]{2}{*}{$\begin{array}{c}\text { Tumor size } \\
(\mathrm{cm} ; \text { mean } \pm S D)\end{array}$} & \multicolumn{2}{|c|}{$\begin{array}{l}\text { Pathological } \\
\text { stage }^{\ddagger} \text { No. }(\%)\end{array}$} & \multicolumn{2}{|c|}{$\begin{array}{c}\text { Fuhrman's nuclear } \\
\text { grade; No.(\%) }\end{array}$} & \multirow[t]{2}{*}{$\begin{array}{l}\text { Ki-67 index } \\
(\text { mean } \pm S D)\end{array}$} \\
\hline & & 1,2 & 3,4 & 1,2 & 3,4 & \\
\hline Negative $(16 ; 42.1)$ & $6.8 \pm 3.3$ & $11(34.4)$ & $5(83.3)$ & $12(46.2)$ & $4(33.3)$ & $5.5 \pm 7.9$ \\
\hline Positive (22; 57.9) & $6.6 \pm 3.9$ & $21(65.6)$ & $1(16.7)$ & $14(53.8)$ & $8(66.7)$ & $5.2 \pm 3.6$ \\
\hline $\mathrm{p}$ & $0.860^{*}$ & \multicolumn{2}{|c|}{$0.026^{\dagger}$} & \multicolumn{2}{|c|}{$0.457^{\dagger}$} & $0.888^{*}$ \\
\hline
\end{tabular}

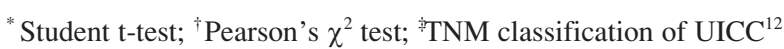

in tumor progression. ${ }^{26}$ It is a widely distributed cell surface glycoprotein expressed as many isoforms arising from a single gene by alternative splicing. One of them is CD44v6, a variant that has been identified as a marker of cancer progression. ${ }^{13}$ A principal ligand for the standard form of CD44 is hyaluronan, but ligands for the variant isoforms are not as well characterized. One of the proposed ligands is osteopontin, a secreted adhesive glycoprotein, expressed by various mesenchymal and epithelial cells, and involved in a variety of physiological functions, as well as in tumorigenesis and metastasis. ${ }^{23}$

Osteopontin contains binding sites for several receptors, including CD44 and integrin $\alpha v \beta 3$, cell surface molecules playing a major role in mediating cell migration and adhesion. ${ }^{20}$ An increase in osteopontin expression levels has been shown to correlate with enhanced malignancy in several in vitro and in vivo studies. ${ }^{1,5,21,24}$ High expression of both adhesion molecules, CD44 and osteopontin, has been shown to correlate with poor prognostic parameters in clear cell type of renal cell carcinoma, which is the most common type of renal cancer. ${ }^{10,18,19,22}$ However, to our knowledge, there are no reports on the expression of these two adhesion molecules in papillary renal cell carcinoma.

The current study was undertaken to investigate the expression of osteopontin and CD44 molecule in papillary renal cell carcinoma, in order to better characterize this rare type of renal cancer, and to compare the results with prognostic parameters.

\section{Materials and methods}

Tumor samples

We examined 50 consecutive nephrectomy specimens in which papillary renal cell tumors had been diagnosed during the routine pathological work from January 1989 till September 2004. Since typing and grading of renal cell carcinoma have markedly changed in the past decade, all hematoxylin-eosin-stained sections from each case were reviewed by two pathologists, followed by exclusion of 3 cases, which did not meet criteria for papillary renal cell car- cinoma diagnosis according to WHO classification. ${ }^{8}$ The tumors were classified as adenoma or carcinoma, after examination of hematoxylin-eosin-stained tissue sections, according to WHO criteria, and graded using the Fuhrman nuclear grading system. ${ }^{16}$ Four cases were excluded on the basis of incomplete clinical data or inadequate archival material, so a total of 43 specimens were finally included in the study. Five tumors consisted of tubulopapillary structures lined by small, cuboidal cells with rounded, uniform nuclei lacking cytological atypia. Tumors were circumscribed, but not encapsulated, without stromal reaction, mitoses were absent or rare. These tumors were classified as adenomas, and the other 38 samples, exhibiting at least $75 \%$ papillary or tubulopapillary architecture, which did not meet the above mentioned criteria, were classified as papillary renal cell carcinoma. Carcinoma samples were further subdived into the type 1 (single-layered small cells with pale cytoplasm and small oval nuclei with inconspicuous nucleoli) and type 2 (pseudostratified large cells with abundant eosinophilic cytoplasm and large nuclei with prominent nucleoli), according to criteria proposed by Delahunt et al. ${ }^{7}$ Tumor stage was defined according to the International Union Against Cancer (IUCC) 1997 tumor-node-metastasis (TNM) classification. ${ }^{12}$

\section{Immunohistochemistry}

For each case of papillary renal cell carcinoma, a representative slide of the tumor and the corresponding paraffin block was selected. Five-micron sections were cut on glass slides (DakoCytomation, Glostrup, Denmark), and air-dried during the night. Following deparaffinization in xylene and rehydration in alcohol, heat-induced epitope retrieval was achieved by immersing slides in $10 \mathrm{mM}$ citrate buffer $(\mathrm{pH}$ 6.0) and boiling for 10 minutes in a pressure cooker. Slides were allowed to cool for 45 minutes, and then pre-incubated with blocking solution containing normal donkey serum (Santa Cruz Biotechnology, Santa Cruz, CA, USA) for osteopontin staining, or normal goat serum (DakoCytomation) for CD44 staining, respectively, for 30 minutes. The staining was performed by indirect immunoperoxidase 

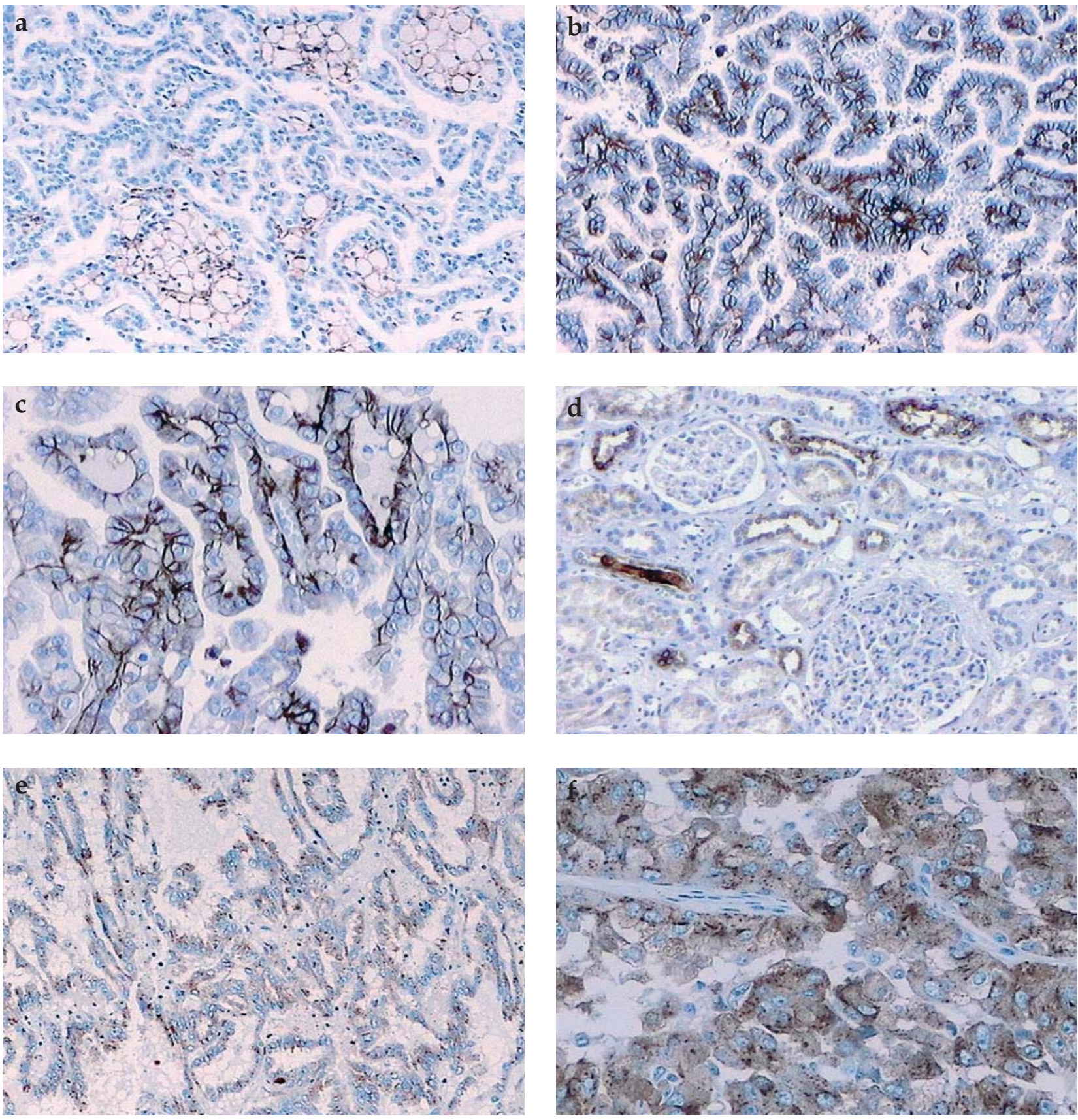

Figure 1. Immunohistochemical expression of CD44s and osteopontin in papillary renal cell carcinoma. Tumor cells are negative for CD44s, while foamy macrophages in tumor stroma are positive (a). Tumor cells are strongly positive for CD44s $(\boldsymbol{b})$ and CD44v6 (c). Normal renal tissue showing staining of epithelial cells in distal tubules and luminal calcifications (d). Cytoplasmic granular positivity in type $1(e)$ and type 2 ( $f$ ) papillary carcinoma cells.

method in an automated immunostainer (DakoCytomation, TechMate ${ }^{\mathrm{TM}}$ Horizon, Glostrup, Denmark) using DakoCytomation LSAB2 HRP system, according to the manufacturer's protocol. Murine monoclonal antibodies against CD44s (clone SFF304, dilution 1:15000) and CD44v6 (clone VFF18, dilution 1:15000) were purchased from Bender MedSystems (Vienna, Austria), and applied overnight at $+4^{\circ} \mathrm{C}$. For negative control, an irrelevant murine monoclonal $\operatorname{IgG}$ antibody was used (DakoCytomation). For positive controls, a staining of intratumoral lymphocytes for CD44s, and urothelium for v6 isoform, was used.

Osteopontin was detected by goat anti-human monoclonal antibody (clone K-20, Santa Cruz Biotechnology, dilution $1: 100$ ), followed by donkey anti-goat IgG as sec- 
ondary antibody (Santa Cruz Biotechnology, dilution 1:250). For a negative control, an irrelevant goat IgG was used (Santa Cruz Biotechnology). Staining of the luminal portion of distal tubular cells and calcifications within renal parenchyma served as a positive control. In some doubtful cases, staining with murine anti-CD68 antibody (clone KP-1, DakoCytomation, 1:200) was performed to distinguish between tumor cells and histiocytes, which, in activated state, are also positive for osteopontin and CD44s. MIB-1 antibody (DakoCytomation, dilution 1:50) was used to analyze nuclear expression of the Ki-67 cell proliferation antigen.

\section{Evaluation of immunohistochemistry}

Immunohistochemical staining results were examined independently by two pathologists, without knowledge of the nuclear grade or other clinicopathological parameters of each individual case. Cases without any detectable staining were considered negative, as well as those with only focal positivity, found in less than $1 \%$ of tumor cells. Positive staining for CD44 molecule and osteopontin was defined as membranous or granular cytoplasmic positivity, respectively, found in more than $1 \%$ of tumor cells. Tumor growth kinetics was determined by immunohistochemical detection of Ki-67 antigen. Ki-67 antigen expression was assessed in areas with the highest density of positive cells, and expressed as Ki-67 labeling index (percentage of positive cells) by scoring 500 tumor cells at high power field. The counting was performed on image analyzer using ISSA 3.1 software (Vams, Zagreb, Croatia).

\section{Statistical analysis}

Statistical analysis was performed using Statistica 6.1 software (StatSoft, Inc., Tulsa, OK, USA). Pearson's $\chi^{2}$ test was used to assess the significance of associations between categorical data. The mean values of continuous data, such as $\mathrm{Ki}-67$ proliferation index and tumor size, were compared by Student's t-test. Statistical differences with $\mathrm{p}$ value less than 0.05 were considered significant.

\section{Results}

\section{Clinicopathological data}

The sex distribution was as follows: 4 men and 1 woman for papillary renal cell adenomas, and 30 men and 8 women for papillary renal cell carcinomas. Tumor size for papillary adenomas was $0.6 \pm 0.2 \mathrm{~cm}$, while papillary carcinomas measured $6.6 \pm 3.6 \mathrm{~cm}$ in diameter. The Fuhrman grading distribution was as follows: 3 grade 1, 23 grade 2, 8 grade 3 , and 4 grade 4 tumors. Pathological staging according to the TNM classification was pT1 in 19 casespT2 in 13 cases, and pT3 in 6 cases.
Immunohistochemical staining in normal renal tissue and papillary renal cell adenomas

In the normal renal parenchyma no staining for CD44s or v6 isoforms was observed, except for a few CD44s- and v6positive tubules, usually in the close vicinity to the tumor tissue. Stromal cells, like lymphocytes and macrophages were also positive for CD44s. Staining was of membranous type, in contrast to staining pattern of osteopontin, which was granular and cytoplasmic. The expression of osteopontin was seen in distal tubular epithelial cells, and was usually most prominent along the luminal side of the cell. Calcifications and stromal cells like macrophages and plasma cells were also positive (Figure 1d). Papillary renal adenomas were negative for CD44s and CD44v6 isoforms, except for one case in which a focal staining of a few tumor cells with anti-CD44s was observed. Staining for osteopontin protein was present in all tumors, although it was generally of lower intensity, and in smaller proportion of tumor cells, comparing to papillary renal cell carcinoma.

\section{Immunohistochemical staining in papillary renal cell carcinomas}

Sixteen samples were negative for CD44s (42\%), while upregulation of CD44s molecule was found in 22 cases $(58 \%)$ (Table 1). Staining pattern was heterogeneous, ranging from weak positivity in part of the tumor to strong and diffuse staining of almost all tumor cells (Figure $1 b$ ). It was always of membranous type, and usually present along the basolateral surface of the cell. CD44v6 was expressed in $12(32 \%)$ tumors, with 8 tumors of type 1 and 4 tumors of type 2 morphology (Figure 1c).

All papillary renal cell carcinomas, except one, were positive for osteopontin (Figure 1e,f). Staining was present in the cytoplasm in the form of granules of various sizes and staining intensity. The granules were distributed either evenly, or were showing perinuclear or perimembranous distribution. The pattern of staining varied between samples and ranged from staining of small number of tumor cells with low intensity to strong and diffuse positivity throughout the tumor. The proportion of positive cells varied with predominant expression in more than $50 \%$ of tumor cells.

\section{Association between CD44 expression} and clinicopathological characteristics

The expression of CD44 molecule was compared to usual prognostic parameters in renal cell carcinomas such as tumor size, Fuhrman nuclear grade, pathological stage, and Ki-67 proliferation index (Table 1). We could find statistically significant association of CD44s expression only with pathological stage $(\mathrm{p}=0.026)$, with higher incidence of CD44s positivity in tumors confined within kidneys (i.e., pT1 or pT2), 
compared to those invading beyond the kidneys (i.e., pT3 or pT4). Other clinicopathological variables were not associated with the expression of the CD44 molecule, neither CD44s (Table 1), nor CD44v6 (data not shown).

Clinicopathological characteristics of papillary renal cell carcinomas in relation to histological type

The results of clinicopathological parameters in relation to 2 morphological types of papillary renal cell carcinoma are shown in Table 2. Mean diameter of type 1 carcinomas was smaller then that of type 2 carcinomas $(6.2 \pm 3.3 \mathrm{~cm}$ versus $7.7 \pm 4.4 \mathrm{~cm}$ ), but the difference was not significant $(p=0.254)$. There was a significant difference in the distribution of nuclear grades and pathological stages between type 1 and type 2 papillary renal cell carcinomas $(\mathrm{p}<0.001$ and $p=0.026$, respectively). The majority of type 1 papillary renal cell carcinomas were of lower nuclear grade and localized to the kidney at the time of diagnosis, whereas type 2 tumors were mostly of higher nuclear grade and frequently presented with locally invasive disease. Analysis of tumor growth fraction showed Ki-67 index to be significantly higher for type $2(10.7 \pm 8.4)$ compared to type 1 tumors $(3.3 \pm 2.8)(\mathrm{p}<0.001)$.

\section{Discussion}

In the present study we demonstrated the upregulation of CD44s and v6 isoforms in papillary renal cell carcinomas, in opposite to adenomas, and the constitutive expression of osteopontin in both types of papillary renal cell tumors. Numerous investigators reported the prognostic significance of CD44s overexpression in clear cell type of renal cell carcinoma, which is the most common type of renal cancer. ${ }^{10,19,22}$ However, there are limited data regarding the expression of CD44 molecule in papillary renal cell carcino$\mathrm{ma}$, and as a rule, the number of cases is too small to achieve relevant conclusion. In addition, papillary carcinomas were always considered as a group, without data for particular tumor type proposed by Delahunt et al. ${ }^{7}$ Our results contrasted with that of Heider et al. who found papillary renal cell carcinoma almost completely devoid of CD44 expression, including the CD44s isoform. ${ }^{15}$ In the study of Terpe et al. on 7 papillary renal cell carcinomas, CD44s, v6 and v9 isoforms were detected only in nuclear grade 2 tumors, while all grade 1 cases were negative. ${ }^{25}$ In our study, the expression of CD44s and v6 isoforms was not associated with nuclear grade, neither considering all tumors as a group, nor for particular types. In contrast to results obtained on clear cell carcinomas, ${ }^{22}$ the expression of CD44s and v6 was associated with lower pathological stage. Furthermore, in type 2, which often presents in higher pathological stages, all CD44s-positive cases presented in low pathological stages. Our findings corroborate those described by Gilcrease et al., ${ }^{10}$ who also
Table 2. Comparison between the two types of papillary renal cell carcinoma

\begin{tabular}{lcccc}
\hline Characteristic & & Type 1 & Type 2 & $p$ \\
\hline $\begin{array}{l}\text { Fuhrman's nuclear } \\
\text { grade; No. (\%) }\end{array}$ & $\begin{array}{l}1,2 \\
2,4\end{array}$ & $\begin{array}{c}25(92.6) \\
2(7.4)\end{array}$ & $\begin{array}{c}1(9.1) \\
10(90.9)\end{array}$ & $<0.001^{*}$ \\
\hline $\begin{array}{l}\text { Pathological stage } \\
\text { (No.; })\end{array}$ & 1,2 & $\begin{array}{c}25(92.6) \\
2(7.4)\end{array}$ & $\begin{array}{c}7(63.6) \\
4(36.4)\end{array}$ & $0.026^{*}$ \\
\hline $\begin{array}{l}\text { Tumor size } \\
(\mathrm{cm}, \text { mean } \pm \text { SD) }\end{array}$ & 3,4 & $6.2 \pm 3.3$ & $7.7 \pm 4.4$ & $0.254^{\dagger}$ \\
\hline $\begin{array}{l}\text { Ki-67 index } \\
(\text { mean } \pm \text { SD) }\end{array}$ & $3.3 \pm 2.8$ & $10.7 \pm 8.4$ & $<0.001^{\dagger}$ \\
\hline
\end{tabular}

"Pearson's $\chi^{2}$ test; 'Student's t-test; ${ }^{\ddagger}$ TNM classification of UICC

found increased expression of CD44s and v6 in papillary renal cell carcinoma versus clear cell carcinoma, and in low versus high tumor stages, although the number of cases was to small to achieve statistical significance. It seems that overexpression of CD44s and v6 isoforms in papillary renal cell carcinoma, although present in higher proportion of cases compared to clear cell carcinoma, does not provide any useful prognostic information.

Growing evidence supports a role for osteopontin as a potential prognostic factor in various human cancers. Osteopontin RNA and protein have been found to be overexpressed in a number of human tumor types, relative to normal tissue, and this overexpression has been associated with progression of the disease and patients' survival. ${ }^{1,5,19,21,24}$ However, there are no reports on osteopontin expression in papillary renal cell carcinoma, except for reporting of one positive well-differentiated papillary renal cell carcinoma case in the study of Brown et al. ${ }^{4}$ Coppola et al. described a correlation between the level of osteopontin expression and tumor stage in renal cell carcinoma, but the type of renal cancer was not mentioned. ${ }^{5}$ We have recently shown the overexpression of osteopontin in $45.5 \%$ of clear cell carcinoma samples, which was associated with well-known predictors of poor outcome: higher nuclear grade, higher pathological stage and high tumor growth kinetics. ${ }^{18}$ All grade 1 clear cell carcinomas were negative for osteopontin, while the number of positive samples increased with transformation to higher nuclear grade. In the present study on the papillary type of renal cancer, the expression of osteopontin was noted in almost all cases, including papillary renal cell adenomas. In the only negative sample of papillary renal cell carcinoma, which was diagnosed in 1989, the positive control, i.e. staining of distal tubules and calcifications, was very weak, probably due to poor quality of paraffin used in the past. Therefore, the lack of osteopontin expression in this particular case could possibly present false negative staining result. The level of expression did not correlate with 
prognostic parameters, as described for clear cell type of renal cancer and malignant tumors from other tissues. ${ }^{1,19,21,24}$

In our papillary carcinoma sample, type 2 morphology of tumors was associated with poor prognostic variables, as has been recently proposed. ${ }^{7}$ However, it does not seem to be related to the expression of osteopontin, which was also present in type 1 carcinomas, as well as in renal cell adenomas.

It is well known that osteopontin promoter is responsive to many agents, including cytokines, growth factors and hormones. ${ }^{6,23}$ Many of the factors that enhance osteopontin expression have in common the fact that they increase Ras expression, and activation of Ras is known to stimulate osteopontin expression. ${ }^{14}$ Increased expression of osteopontin itself can lead, via osteopontin-mediated signaling, to upregulation of other genes important to tumor progression and metastasis. ${ }^{23}$ Experimental results suggest that the role of osteopontin in tumor development is complex, and may be affected by a variety of parameters, including tumor type and growth factor milieu, which may reflect a role of the tumor microenvironment in determining the effects of osteopontin. ${ }^{23}$ In papillary renal cell tumors, overexpression of a candidate gene associated with the polysomy of chromosome 7 , could be the c-met proto-oncogene, ${ }^{17}$ which encodes for the receptor for hepatocyte growth factor (HGF), a multifunctional cytokine stimulating cell proliferation and motility. Recently, osteopontin has been identified as a protein whose expression was upregulated upon HGF stimulation, and it was proposed that, together with other molecules, osteopontin might contribute to HGF-induced tumor growth. ${ }^{3}$ Therefore, it is possible that constitutive expression of osteopontin in papillary renal cell carcinoma could be related to mutation or overexpression of c-met protein.

In conclusion, in the present study we have shown for the first time the upregulation of CD44 molecule and osteopontin in a series of papillary renal cell carcinoma. Although both adhesive molecules were presented in higher percentage of tumors compared to clear cell type, they do not seem to have prognostic importance as described for the most common type of renal cell carcinoma. The results support different biology and different factors involved in progression of these two types of renal cell carcinoma. However, our finding of constitutive expression of osteopontin in papillary renal cell carcinoma could contribute to the differential diagnosis of difficult cases.

\section{References}

1. Agrawal D, Chen T, Irby R, et al: Osteopontin identified as lead marker of colon cancer progression, using pooled sample expression profiling. J Natl Cancer Inst 94:513-521, 2002

2. Amin MB, Corless CL, Renshaw AA, et al: Papillary (chromophil) renal cell carcinoma: histomorphologic characteristics and evaluation of conventional pathologic prognostic parameters in 62 cases. Am J Surg Pathol 21:621-635, 1997

3. Ariztia EV, Subbarao V, Solt DB, et al: Osteopontin contributes to hepatocyte growth factor-induced tumor growth and metastasis formation. Exp Cell Res 288:257-267, 2003
4. Brown LF, Papadopoulos-Sergiou A, Berse B, et al: Osteopontin expression and distribution in human carcinomas. Am J Pathol 145:610-623, 1994

5. Coppola D, Szabo M, Boulware D, et al: Correlation of osteopontin protein expression and pathological stage across a wide variety of tumor histogenesis. Clin Cancer Res 10:184-190, 2004

6. Craig AM, Denhardt DT: The murine gene encoding secreted phosphoprotein 1 (osteopontin): promoter structure, activity, and induction in vivo by estrogen and progesterone. Gene 100:163-171, 1991

7. Delahunt B, Eble JN: Papillary renal cell carcinoma: A clinicopathologic and immunohistochemical study of 105 tumors. Mod Pathol 10:537-544, 1997

8. Eble JN, Sauter G, Epstein JI, Sesterhenn IA: WHO Classification of Tumours. Pathology and Genetics of Tumours of the Urinary System and Male Genital Organs. 6st vol. IARC Press, Lyon (France), 2004, pp: $9-87$

9. Fuhrman S, Lasky L, Lumas C: Prognostic significance of morphologic parameters in renal cell carcinoma. Am J Surg Pathol 6:655-663, 1982

10. Gilcrease MZ, Guzman-Paz M, Niehans G, et al: Correlation of CD44s expression in renal clear cell carcinomas with subsequent tumor progression or recurrence. Cancer 86:2320-2326, 1999

11. Glukhova L, Goguel AF, Chudoba I, et al: Overexpression of 7q31 and $17 \mathrm{q}$ in renal cell carcinoma. Genes Chromosomes Cancer 5:348356, 1998

12. Guinan P, Sobin LH, Algaba F, et al: TNM staging of renal cell carcinoma: Workgroup No. 3. Union International Contre le Cancer (UICC) and the American Joint Committee on Cancer (AJCC). Cancer 80:992993, 1997

13. Gunthert U, Stauder R, Mayer B, et al: CD44 variant isoforms involved in human tumor progression? Cancer Surv 24:19-42, 1995

14. Guo X, Zhang YP, Mitchell DA, et al: Identification of a ras-activated enhancer in the mouse osteopontin promoter and its interaction with a putative ETS-related transcription factor whose activity correlates with the metastatic potential of the cell. Mol Cell Biol 15:476487, 1995

15. Heider $K H$, Ratschek $M$, Zatloukal $K$, et al: Expression of CD44 isoforms in human renal cell carcinomas. Virchows Arch 428:267-273, 1996

16. Kovacs G, Fuzesi L, Emanual A, et al: Cytogenetics of papillary renal cell tumors. Genes Chromosomes Cancer 3:249-255, 1991

17. Lubensky IA, Schmidt L, Zhuang Z, et al: Hereditary and sporadic papillary renal carcinomas with c-met mutations share a distinct morphological phenotype. Am J Pathol 155:517-526, 1999

18. Lucin K, Matusan K, Dordevic G, et al: The expression of osteopontin in renal cell carcinomas. In: Proceedings of the Second Intercontinental Congress of Pathology. (Eds: Soares F, Vassallo J, Torres LFB), Medimond, 2004, p: 151-154

19. Lucin K, Matusan K, Dordevic G, et al: Prognostic significance of CD44 molecule in renal cell carcinoma. Croat Med J 45:703-708, 2004

20. Oldberg A, Franzen A, Heinegard D: Cloning and sequence analysis of rat bone sialoprotein (osteopontin) cDNA reveals and Arg-Gly-Asp cell-binding sequence. Proc Natl Acad Sci USA 83:8819-8823, 1986

21. Pan HW, Ou YH, Peng SY, et al: Overexpression of osteopontin is associated with intrahepatic metastasis, early recurrence, and poorer prognosis of surgically resected hepatocellular carcinoma. Cancer 98:119127, 2003

22. Paradis V,Ferlicot S, Ghannam E, et al: CD44 is an independent prognostic factor in conventional renal cell carcinomas. J Urology 161:1984-1987, 1999

23. Rittling $S R$, Chambers $A F$ : Role of osteopontin in tumour progression. Br J Cancer 90:1877-1881, 2004

24. Rudland PS, Platt-Higgins A, El-Tanani M, et al: Prognostic significance of the metastasis-associated protein osteopontin in human breast cancer. Cancer Res 62:3417-3427, 2002

25. Terpe HJ, Storkel S, Zimmer U, et al: Expression of CD44 isoforms in renal cell tumors. Positive correlation to tumor differentiation. Am J Pathol 148:453-463, 1996

26. Zbigniew R, Serge J: CD44 and the adhesion of neoplastic cells. J Clin Pathol: Mol Pathol 50:57-71, 1997 